The Psychological Record, 2009, 59, 389-406

\title{
TESTING THE VALIDITY OF THE IMPLICIT RELATIONAL ASSESSMENT PROCEDURE AND THE IMPLICIT ASSOCIATION TEST: MEASURING ATTITUDES TOWARD DUBLIN AND COUNTRY LIFE IN IRELAND
}

\author{
Dermot Barnes-Holmes, Deirdre Waldron, \\ and Yvonne Barnes-Holmes \\ National University of Ireland, Maynooth \\ Ian Stewart \\ National University of Ireland, Galway
}

\begin{abstract}
The current study aimed to test the validity of the Implicit Relational Assessment Procedure (IRAP), as compared to the Implicit Association Test (IAT), by assessing the attitudes of Dublin dwellers and rural dwellers toward Dublin and country life. Discrimination between the two groups for the IAT was marginally significant. The IRAP discriminated significantly between the two groups based on an interaction effect, which showed that rural dwellers had a strong bias toward country life but Dublin dwellers did not show the same bias toward Dublin life. The IRAP data correlated moderately with the explicit measures, but the IAT did not. The findings support the IRAP as a potentially useful measure of implicit attitudes.
\end{abstract}

The currently most popular and well-researched measure of so-called implicit attitudes is the Implicit Association Test, or IAT (Greenwald, McGhee, \& Schwartz, 1998). The core assumption underpinning the method is that individuals should respond quickly when asked to emit a similar response for two concepts that are closely associated in memory, but should respond more slowly when the two concepts are less closely associated. The first IAT study by Greenwald et al. (1998) asked participants in one task to categorize the names of flowers with positive words and the names of insects with negative words, but in a second task these categorizations were reversed (flowers-negative and insects-positive). The predicted IAT effect was observed: The participants responded faster on flower-positive and

We would like to thank two anonymous reviewers for their thoughtful and constructive reviews of the original manuscript.

Correspondence concerning this article should be addressed to Dermot Barnes-Holmes, Department of Psychology, National University of Ireland, Maynooth, Co. Kildare, Ireland. E-mail: Dermot.Barnes-Holmes@nuim.ie. 
insect-negative trials than on the reversed counterparts. ${ }^{1}$ The assumption here, of course, was that flowers are positive and insects are negative for most people. Numerous subsequent studies have replicated this basic finding across a wide range of domains (see Nosek, Greenwald, \& Banaji, 2006, for a recent review), and most controversially, the IAT effect has often been found in socially sensitive areas such as racism (e.g., Dasgupta \& Greenwald, 2001).

Although the IAT is now the most popular test of implicit attitudes, a widely recognized weakness is that it provides a measure of relative associative strength, which creates a lack of precision in determining the nature of the attitudes under study (see De Houwer, 2003). If, for example, participants respond more quickly on flower-positive and insect-negative trials than on the reversed counterparts (i.e., flower-negative and insectpositive), this result could indicate more than one outcome. Participants may (a) like flowers and dislike insects, or (b) like both flowers and insects but like the former more than the latter, or (c) dislike flowers and insects but dislike the latter more than the former. In order to measure implicit attitudes to individual stimuli, therefore, a nonrelative measure is required, and a number of researchers have attempted to develop such tests, including, for instance, the Extrinsic Affective Simon Test (EAST; De Houwer, 2003) and the Go/No-Go Association Task (GNAT; Nosek \& Banaji, 2001).

Another nonrelative measure that has been offered recently is the Implicit Relational Assessment Procedure (IRAP; Barnes-Holmes, BarnesHolmes, Power, Hayden, Milne, \& Stewart, 2006; Barnes-Holmes, Hayden, Barnes-Holmes, \& Stewart, 2008; Barnes-Holmes, Murtagh, Barnes-Holmes, \& Stewart, in press; McKenna, Barnes-Holmes, Barnes-Holmes, \& Stewart, 2007; Vahey, Barnes-Holmes, Barnes-Holmes, \& Stewart, in press). The theoretical basis for the IRAP, as procedure and effect, is found in relational frame theory (RFT), which defines the core units of human language and cognition not as associations per se, but as derived stimulus relations (Hayes, Barnes-Holmes, \& Roche, 2001). One of the main methodologies to emerge from RFT is the relational evaluation procedure (REP). This procedure requires that participants report on a stimulus relation that is presented on a given trial, and it has now been employed in a number of studies on reasoning and other forms of higher cognition (O'Hora, BarnesHolmes, Roche, \& Smeets, 2004; O’Hora, Peláez, Barnes-Holmes, \& Amesty, 2005; Stewart, Barnes-Holmes, \& Roche, 2002, 2004). Critically, the REP provided a foundation for the development of the IRAP, which in essence is a combination of the IAT and the REP (see Barnes-Holmes et al., 2006; Barnes-Holmes et al., 2008).

The IRAP involves presenting words, pictures, or statements on each trial, and participants are required to respond to these stimuli in a manner that either agrees or disagrees with their preexperimentally established verbal relations. It is predicted that response latencies will be shorter across trials that agree with established verbal relations

1 Consistent with conventional practice in this research area, the basic acronym (e.g., IAT) is used to refer to the experimental procedure, whereas the outcome or measure is referred to as an effect (e.g., IAT effect). The acronym alone will be used, however, if the wider verbal context clearly indicates the effect rather than the procedure. 
(consistent trials) than across trials that do not (inconsistent relations). ${ }^{2}$ The first study to employ the IRAP (Barnes-Holmes et al., 2008) involved presenting four words on each trial: an attribute stimulus (i.e., "Pleasant" or "Unpleasant"), a positively or negatively valenced target stimulus (e.g., "Caress" or "Hate"), and two relational terms (i.e., "Similar" and "Opposite"). The response-contingent feedback for consistent blocks of trials coordinated with previously established relations but opposed such relations during inconsistent blocks. As predicted, response latencies were shorter for consistent than for inconsistent trials (e.g., participants responded more quickly to Unpleasant-Hate-Similar than to Unpleasant-Hate-Opposite). This basic IRAP effect has now been replicated across a small number of other studies (see Barnes-Holmes et al., 2006; Barnes-Holmes et al., 2008; Barnes-Holmes, Murtagh, et al., in press; McKenna et al., 2007; Vahey et al., in press). Although the initial findings are promising, research on the IRAP as an implicit measure is still quite limited, and thus further empirical inquiry is needed before its reliability and validity may be determined. The primary purpose of the current study was to contribute toward this research program.

One strategy for determining the validity of an implicit measure is to employ the known-groups approach. In effect, one can test the validity of a measure by using it to assess two groups that differ clearly along some dimension. If the measure successfully discriminates between the two groups based on the relevant dimension, then it acquires some predictive validity (De Houwer \& De Bruycker, 2007). The aim of the current study was to compare the sensitivity of the IAT and IRAP effects as measures of implicit attitudes using a known-groups comparison. The relevant dimension selected for the current research was attitudes toward Dublin and country life among Irish individuals who resided either in the city or in a rural area. Although these specific attitudes were, in one sense, tangential to the primary purpose of the current study (i.e., testing the validity of implicit measures), the Dublincountry dimension was specifically selected for two reasons.

First, there is a long-standing tradition of good-natured antagonism between Dublin and rural dwellers in Ireland. Typically, both groups will declare great pride and attachment to their city or country area, and frequently this is bolstered by allegiance to a particular sports team associated with the Gaelic Athletic Association (O'Connor, 2005). Consequently, it may be predicted that Dublin dwellers will have a more positive attitude toward Dublin life than rural dwellers and, conversely, the rural dwellers will have a more positive attitude toward rural life than Dublin dwellers.

Second, the Dublin/rural comparison was deemed to be noncontroversial, in that participants would be expected to be relatively open about, and perhaps even proud of, their pro-Dublin or pro-country attitudes. In those contexts in which explicit attitudes are not particularly sensitive and there are few social reasons to hide them, a correlation between explicit and implicit measures may be expected (De Houwer \& De Bruycker, 2007). In the context of

2 As indicated above, a widely recognized limitation to the IAT is that it provides a measure of relative associative strength, and thus only relative preferences may be inferred from the measure. In contrast, the IRAP typically requires that participants respond to each attitude object in either a positive or negative manner on separate trials. Consequently, separate IRAP effects may be calculated for each attitude object, thus providing greater analytic precision than the IAT (see Barnes-Holmes, Murtagh, et al., in press; Vahey et al., in press). 
the current study, therefore, it should be possible to determine if the IAT and IRAP effects are equally or differentially effective in predicting pro-Dublin versus pro-country explicit attitudes.

All of the participants in the current study completed a questionnaire to provide an explicit measure of their attitudes toward city and country life. Subsequently, they each completed IAT and IRAP tasks that were designed to assess implicit attitudes toward the two domains. The IAT task involved blocks in which participants were required to classify target stimuli as associated with positive or negative attributes and with Dublin or country life. In two of the blocks "Dublin Life" and "Positive" were assigned to one key, and "Country Life" and "Negative" were assigned to a second key. In another two blocks, the assignments of "Dublin Life" and "Country Life" were reversed (Dublin-Negative, Country-Positive). The difference in response latency between these types of trials should thus provide a measure of the relevant implicit attitudes; for example, associating "Positive" more quickly with "Dublin" than with "Country" would indicate a pro-Dublin bias.

The IRAP task involved responding with "Similar" or "Opposite" to positive or negative target stimuli when presented with the category labels "Dublin Life" or "Country Life." The blocks alternated between pro-Dublin and pro-country blocks in which the feedback contingencies either agreed or conflicted with the participants' own attitudes. For pro-Dublin blocks, for example, participants were required to respond "Similar" to "Dublin LifeGood" and on pro-country blocks to respond "Opposite." If a participant responded more quickly on the pro-Dublin than on the pro-country blocks, this was taken to indicate a pro-Dublin bias.

The primary aims of the present research were (a) to establish if both the IAT and IRAP effects discriminate between Dublin and rural dwellers' attitudes toward Dublin and country life, (b) to establish each measure's internal reliability, (c) to determine if the two implicit measures predict explicit attitudes and also correlate with each other, and (d) to determine if each of the implicit tests provides increased predictive validity over the explicit measures.

\section{METHOD}

\section{Participants}

Twenty-six individuals completed the experiment; 5 others volunteered but their data were discarded for reasons explained subsequently. The final sample included 13 Dublin dwellers and 13 rural dwellers, ages 17 to 36 years (Dublin dwellers, $M=23$ years; rural dwellers, $M=25$ years). Participants were designated as Dublin or rural dwellers based on their self-reported home addresses; all participants had resided at these addresses for at least 5 years prior to the study. Participants who reported that they lived in the city center or a suburban area of Dublin were classified as Dublin dwellers. Participants who reported that they lived in a village, on a farm, or in a farming area were classified as rural dwellers. All participants completed an IAT and an IRAP task, the order of which was counterbalanced across participants.

\section{Apparatus and Materials}

The research was conducted in the experimental laboratories of the 
Department of Psychology, National University of Ireland, Maynooth. The IRAP and IAT tasks were presented on Dell personal computers with Intel Pentium 4 processors, Qwerty keyboards, and standard 16-in. monitors. The IRAP and IAT computer programs presented stimuli and recorded responses (software available from the first author upon request).

The stimuli employed with the IAT task consisted of a series of 12 words that were deemed to be highly associated with either Dublin life or country life and a further set of 12 words that were classified as positively or negatively valenced (see Table 1). The same set of 6 positive and 6 negative target words were used for the IRAP task. These word sets were chosen based on pilot work conducted with individuals who did not participate in the subsequent experiment. A five-page, hard-copy questionnaire was also used, which included city and country preference scales and a series of demographic questions (all materials available from the first author upon request). The preference scales consisted of two feeling thermometers on which participants were asked to rate how warm $\left(100^{\circ}\right)$ or cold $\left(0^{\circ}\right)$ they felt toward city life and country life and two 7-point Likert scales on which they were asked to rate the pleasantness of city and country life $(-3=$ extremely unpleasant, 0 = neutral, +3 = extremely pleasant).

Table 1

Target-Word Sets Used in the IAT and IRAP Tasks

\begin{tabular}{|c|c|c|c|}
\hline Positive & Negative & Dublin Life & Country Life \\
\hline Good & Bad & Grafton Street $^{a}$ & Cattle Herd \\
\hline Happy & Sad & Heuston Station ${ }^{b}$ & Little Stream \\
\hline Enjoyable & Hateful & The Luas ${ }^{c}$ & Mountain Range \\
\hline Likeable & Awful & Stephen's Green d & Green Field \\
\hline Pleasant & Unpleasant & O'Connell Bridge e & Small Village \\
\hline Great & Miserable & Temple Bar ${ }^{f}$ & The Farm \\
\hline
\end{tabular}

${ }^{a}$ The main shopping street on the south side of the city. ${ }^{b}$ One of the two main train stations. ' The name of the city's tram system. ${ }^{d}$ A famous small park located at the end of Grafton Street. e The city's most famous bridge. ${ }^{f}$ The city's main district for pubs, restaurants, and nightclubs.

\section{Procedure}

\section{Experimental Overview}

Each participant completed the tasks individually. After receiving a brief explanation of what the study involved and providing informed consent, participants were asked to complete the five-page questionnaire. Responses to the demographic questions determined to which category participants were assigned: Dublin dweller or rural dweller. All participants completed both IAT and IRAP tasks. Half of the participants were presented with the IAT first and the other half with the IRAP first, with a break of at least 5 mins between tasks. Each task contained blocks of trials that were deemed to be consistent with either a pro-Dublin or a pro-country bias. (In accordance with standard practice, the interval between blocks was determined by the participant.) The order in which pro-Dublin or pro-country blocks were presented within both the IAT and the IRAP was also counterbalanced across participants. 


\section{IAT Task}

The IAT computer program employed in the current study was identical in all respects to the generic IAT software available for download from Tony Greenwald's personal Web page (http://faculty.washington.edu/agg/iat_ materials.htm). A detailed description of this generic IAT procedure has been provided elsewhere (O’Toole, Barnes-Holmes, \& Smyth, 2007), and thus a less detailed version will be presented here.

The IAT task began with a set of instructions presented on the computer screen. Participants were asked to read through them carefully and ask any questions before beginning. It was explained that the task involved participants sorting words as they appeared by assigning them to a category, with the category labels appearing on the top left and right corners of the computer screen. The "d" key represented the category on the left, and the "k" key represented the category on the right. Participants were instructed to categorize the words as fast as they could, pressing the "d" key with their left index finger and the " $k$ " key with their right index finger. They were also asked to pay attention to the top category labels, as they could switch sides from one block of trials to the next.

In addition, the instructions stated that the task would involve classifying words as either "Positive" or "Negative," and a second task would involve classifying a further set of words as relating either to "Dublin Life" or "Country Life." Participants were asked to assign the items to the group in which they appeared to belong. Finally, participants were informed that if they pressed the wrong key, a red " $\mathrm{X}$ " would appear in the middle of the screen. To remove the red "X," they would have to press the correct key, thus assigning the word to its correct category.

\section{Pro-Dublin to Pro-Country Sequence}

Block 1. The IAT consisted of seven blocks, with the pro-Dublin to procountry IAT beginning with a block involving positive and negative word classifications. The "Positive" label appeared at the top left of the screen and the "Negative" label at the top right. (The left-right positioning of stimuli was counterbalanced across participants, but for ease of exposition only one pattern will be described here.) The target stimuli appeared in green font in the middle of the screen. To assign the target stimulus "Pleasant," for example, to its correct category of "Positive," participants were required to respond by pressing the "d" key. If the correct key was pressed, the target stimulus was immediately removed and $400 \mathrm{~ms}$ later the next target appeared. If the " $\mathrm{k}$ " key was pressed, a red " $\mathrm{X}$ " appeared under the target word. To remove the red " $X$ " and the target word and proceed to the 400-ms intertrial interval, the participant had to press the correct "d" key. The response time between the presentation of the target stimulus and the pressing of the correct key was recorded by the program. Block 1 consisted of 24 trials-the 12 target words presented in a quasi-random order with each word appearing twice. When the final trial had been presented, the screen cleared and the percentage of correct responses and median response time for that block were presented on screen. This type of feedback was presented after all seven blocks of trials.

Block 2. The second block was similar to the first, except that it involved categorizing words as either "Dublin Life" or "Country Life." Thus, "Dublin 
Life" replaced "Positive" and "Country Life" replaced "Negative" on the screen, and the 12 words for Dublin or country life, which appeared in blue, were presented as target stimuli (see Table 1). All other features of the procedure were identical to Block 1, with participants assigning all of the target words to their correct category as quickly as possible.

Block 3. The third block was similar but more complex than the first two because it involved a combination of the two previous tasks. The label in the top left-hand corner now read "Dublin Life or Positive" and the top right label read "Country Life or Negative." The block again consisted of 24 trials, but a word from the positive/negative set or a word from the Dublin/ country set could appear in the middle of the screen. Targets were presented quasi-randomly with the constraint that each target appeared once across the 24 trials. Participants were thus required to categorize "Dublin Life" and "Positive" targets to the left ("d" key) and "Country Life" and "Negative" targets to the right ("k" key).

Block 4. This block was similar to the previous block, except that it consisted of 48 trials (rather than 24), and each target word was presented twice in a quasi-random order.

Block 5. This block was similar to Block 1, except that the position of the "Positive" and "Negative" labels was reversed, and 48 trials were presented.

Block 6. This block was identical to Block 3, except that the reversed positions of the "Positive" and "Negative" labels employed in Block 5 were used. Participants were thus required to categorize "Dublin Life" and "Negative" targets to the left ("d" key) and "Country Life" and "Positive" targets to the right ("k" key).

Block 7. This final block was similar to Block 6, except that it consisted of 48 trials (rather than 24), and each target word was presented twice in a quasi-random order.

The IAT task concluded with a short message informing participants that the sorting tasks were completed and that they should report to the experimenter.

\section{Pro-Country to Pro-Dublin Sequence}

The procedure for this sequence was similar to that described for the pro-Dublin to pro-country sequence, except that the positions of Blocks 1, 3, and 4 were switched with those of 5,6 , and 7 , respectively.

\section{IRAP Task}

The IRAP program began with a set of instructions that described the task by illustrating the layout of the screen and explaining the response options (available from the first author upon request). The instructions informed participants that on each trial one of two labels, "Dublin Life" or "Country Life," would appear at the top of the screen along with a single word presented in the center of screen. Participants were also told that the response options "Similar" and "Opposite" would appear at the bottom of the screen, and they were required to choose one of these options on each trial by pressing either the " $d$ " or " $k$ " key. They were told that the left-right positions of these response options would switch randomly from trial to trial. The instructions also explained that the IRAP consisted of four different trial types, and illustrated examples of these were provided. Participants were 
informed that they sometimes would be required to respond in a way that was consistent with their beliefs and at other times they would have to respond in a way that was inconsistent with their beliefs. (Note, however, that at no point were participants informed which part of the experiment would be contradictory to their beliefs.) They were assured, however, that this was part of the experiment and it was important for them to respond as quickly and accurately as possible on all trials of the IRAP. The instructions also informed participants that correct responses would allow them to progress to the next trial, but incorrect responses would produce a red " $\mathrm{X}$ " in the middle of the screen, which could only be removed by pressing the correct key.

\section{Pro-Dublin to Pro-Country Sequence}

The IRAP task consisted of a minimum of two practice blocks and a fixed set of six test blocks. Each block presented the same 24 trials, comprised of what are defined as four different trial types (see Figure 1). In the pro-Dublin to procountry condition, the first block was designed to be consistent with a pro-Dublinlife bias (e.g., Dublin Life-Good-Similar; Dublin Life-Bad-Opposite; Country Life-Good-Opposite; Country Life-Bad-Similar). The feedback contingencies alternated from block to block between pro-Dublin and pro-country. Thus in the second block, for example, the correct responses were as follows: Dublin LifeGood-Opposite, Dublin Life-Bad-Similar, Country Life-Good-Similar, Country Life-Bad-Opposite. Before each new block began, the participants were informed that the previously correct and incorrect answers would be reversed.
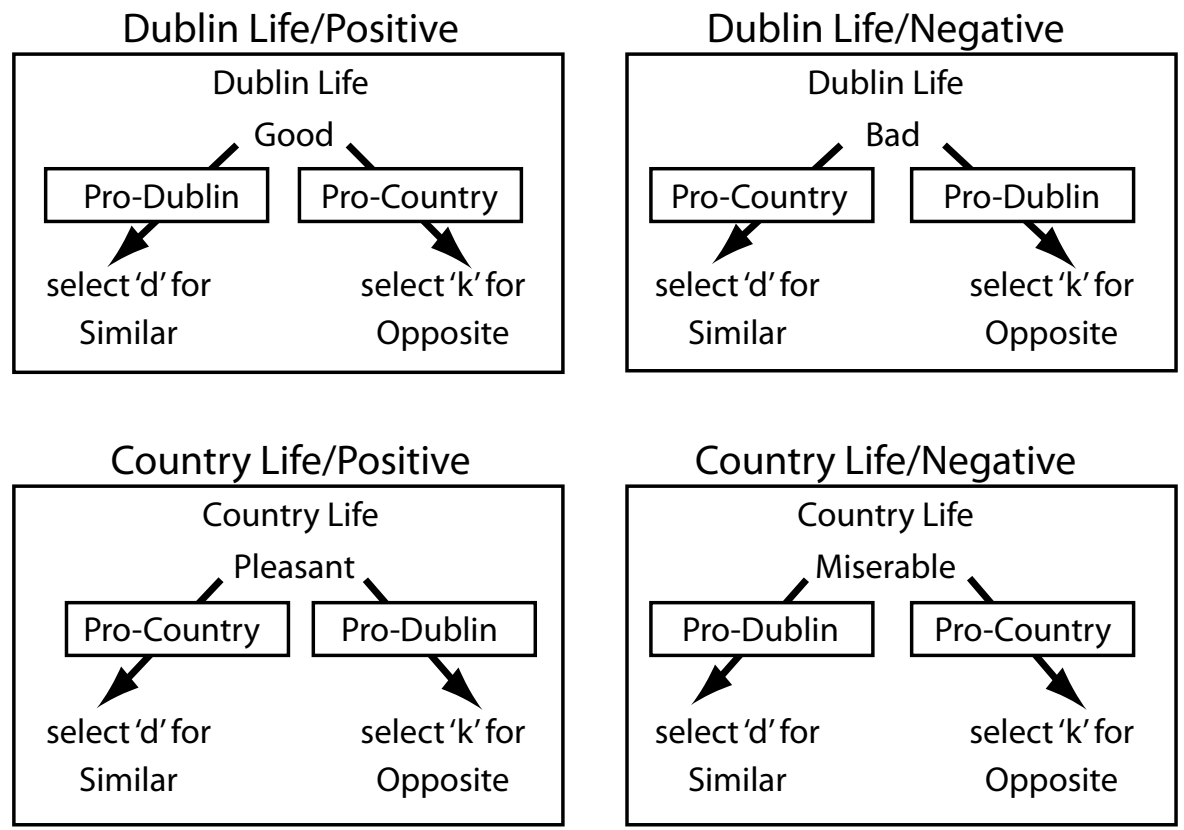

Figure 1. Examples of the four IRAP trial types. The category label (Dublin Life or Country Life), target word (good, bad, pleasant, miserable, etc.), and response options (Similar and Opposite) appeared simultaneously on each trial. Arrows with superimposed text boxes indicate which responses were deemed pro-Dublin or pro-country (boxes and arrows did not appear on screen). 
Each IRAP block consisted of 24 trials, with each target stimulus presented once in the presence of each of the two labels. The trials were presented quasi-randomly with the constraint that none of the four trial types could be presented twice in succession. The positioning of the two response options was also quasi-random in that they could not appear in the same position three times in succession.

On-screen feedback was provided after each block. For the first two practice blocks, participants were informed that it was a practice phase and errors were expected. Participants were required to reach a standard of $80 \%$ correct responses and a median response time of less than $3000 \mathrm{~ms}$. These criteria were used to ensure that participants understood and were complying with the IRAP instructions. If participants failed to achieve the two criteria for either of the two practice blocks, the required standard and the standard of responding they had achieved were presented on the screen. Participants were allowed three attempts to achieve the practice criteria, and if they failed to do so, they were thanked and debriefed and their data were discarded. (Three participants were removed from the study on this basis.) Participants who did achieve the practice criteria proceeded to the six test blocks.

The procedure for the first test block was similar to the first practice block (pro-Dublin), except that on-screen instructions informed participants that the next phase was a test and to "go quickly," although making "a few errors is okay." The second test block was similar to the second practice block (pro-country) but with the modified instructions to go quickly. Test Blocks 3 and 5 were the same as Block 1 (pro-Dublin), and Test Blocks 4 and 6 were the same as Block 2 (pro-country). No performance criteria were applied during the test blocks in order to proceed, but if a participant's performance fell below $80 \%$ accuracy or exceeded $3000 \mathrm{~ms}$ for any test block, the data for that participant were discarded. (Two participants were removed from the study on this basis.) When all six test blocks had been completed, participants reported to the researcher.

\section{Pro-Country to Pro-Dublin Sequence}

Half of the participants were exposed to a pro-country to pro-Dublin IRAP sequence. The procedure was the same as the one described for the pro-Dublin to pro-country sequence, except that the first practice and first test blocks commenced with pro-country feedback contingencies and then alternated across successive blocks between pro-Dublin and pro-country feedback.

\section{RESULTS}

\section{Overview of Data Analyses}

The data analyses for the IAT, the IRAP, and then the explicit measures are presented first. Analyses of variance are used to determine if the Dublin and rural dwellers' responses differed significantly on each of the measures. In addition, one-sample $t$ tests are used to determine if each of the IAT and IRAP effects differed significantly from zero. Split-half correlations are used to assess the internal reliability of the two implicit measures (i.e., by correlating effects calculated from odd trials with effects calculated from even trials). Correlational analyses between the explicit and implicit measures, and 
between the IAT and IRAP, are then presented. Finally, the results of a series of logistic regression analyses are used to determine if the implicit measures provide increased predictive validity over and above that provided by the explicit measures.

\section{IAT Data}

The primary datum was response latency, defined as the time in milliseconds that elapsed between the onset of the trial and a correct response emitted by a participant. To control for individual variations in speed of responding that may act as a possible confound when analyzing between-group differences, the response latency data for each participant were transformed into $D$ scores using the $D$ algorithm developed by Greenwald, Nosek, and Banaji (2003). The version of the $D$ algorithm employed in the current study was computed as follows: (1) Latencies above 10,000 ms from the data set were eliminated; (2) all data for a participant were removed if he or she produced more than $10 \%$ of trials with latencies less than $300 \mathrm{~ms}$; (3) means for trials in each of the four blocks, 3, 4, 6, and 7, were computed; (4) one standard deviation was calculated for all trials in Blocks 3 and 6, and another for Blocks 4 and 7; (5) the difference scores between Blocks 3 and 6 and between Blocks 4 and 7 were computed, taking the pro-Dublin from the pro-country blocks; (6) each difference score was divided by its associated standard deviation from step 4; and (7) these two scores were added together and divided by two. A positive $D$ score signifies a preference for Dublin life over country life, whereas a negative score indicates a preference for country life over Dublin life.

The data from all 26 participants were included in the analyses. The overall mean $D$ scores for the Dublin and rural groups are presented in Figure 2. The IAT effects were in the predicted directions, positive for Dublin and negative for rural. A one-way between-participants analysis of variance (ANOVA) was used to compare the $D$ scores from the two groups, and this proved to be marginally significant, $F(1,24)=4.19, p=0.05, \eta^{2}=.15$. Two one-sample $t$ tests were conducted to determine if the $D$ scores for each group differed significantly from zero. The results were nonsignificant for the Dublin group, $t(12)=.91, p=.38$, but significant for the rural group, $t(12)=-.26, p=.02$. Overall, therefore, the IAT's discrimination between the two groups was marginal, and only the rural group showed a significant IAT pro-country effect.

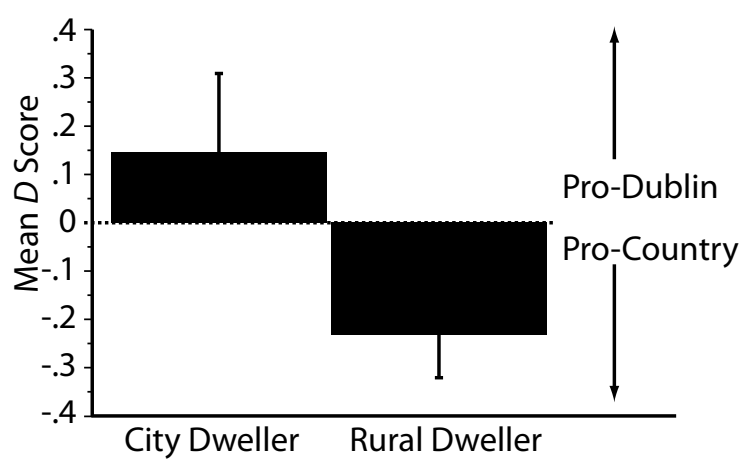

Figure 2. Mean IAT D scores, with standard error bars, for Dublin- and rural-dweller groups. A positive $D$ score indicates a pro-Dublin bias and a negative score indicates a pro-country bias. 


\section{Split-Half Reliability}

To assess the internal consistency of the IAT, a split-half reliability score was calculated for the $D$-IAT measure. Two scores were first calculated in the same way as for the $D$ score, except that the algorithm described previously was applied separately to odd trials and to even trials. The split-half correlation between odd and even scores, applying a Spearman-Brown correction, proved to be moderate and significant $(r=.46, n=26, p<.01)$, indicating a reasonable level of internal consistency.

\section{IRAP Data}

Similar to the IAT, the primary datum was response latency, defined as the time in milliseconds that elapsed between the onset of the trial and a correct response emitted by a participant. The response latency data for each participant were transformed into $D$-IRAP scores using an adaptation of the Greenwald et al. (2003) $D$ algorithm described above (see Barnes-Holmes et al., in press; Cullen \& Barnes-Holmes, 2008; Vahey et al., in press). The steps involved in calculating the $D$-IRAP scores were as follows: (1) Only response-latency data from the six test blocks were used; (2) latencies above 10,000 ms were removed from the data set; (3) if the data from a participant contained more than $10 \%$ of test block trials with latencies less than $300 \mathrm{~ms}$, that participant was removed from the analyses; (4) 12 standard deviations for the four trial types were calculated: 4 for the response latencies from Test Blocks 1 and 2, 4 from the latencies from Test Blocks 3 and 4, and a further 4 from Test Blocks 5 and 6; (5) 24 mean latencies were then calculated for the four trial types in each test block; (6) difference scores for each of the four trial types were calculated for each pair of test blocks by subtracting the mean latency of the pro-Dublin test block from the mean latency of the corresponding pro-country test block; (7) each difference score was then divided by its corresponding standard deviation from step 4, yielding $12 \mathrm{D}$-IRAP scores, one score for each trial type for each pair of test blocks; (8) four overall trial type $D$-IRAP scores were calculated by averaging the three scores for each of the four trial types across the three pairs of test blocks; (9) two $D$-IRAP scores, one for Dublin and one for Country, were then calculated by averaging the two Dublin and then the two Country trial type scores; and (10) an overall $D$-IRAP score was calculated by averaging all 12 trial type $D$-IRAP scores from step 7.

The data from all 26 participants were included in the analyses. The four overall mean $D$-IRAP scores for the Dublin and rural groups are presented in Figure 3. The IRAP effect for both groups was positive for Dublin and negative for Country. That is, both groups responded "Similar" more rapidly than "Opposite" to Dublin-Positive and Country-Positive trials and responded "Opposite" more rapidly than "Similar" to Dublin-Negative and Country-Negative trials. In short, both groups responded positively toward both Dublin and country life. Nevertheless, the pro-country $D$-IRAP score for the rural dwellers was more than twice that of the Dublin dwellers. (The pro-Dublin score only differed slightly across the two groups.) This suggests that although both the Dublin and rural dwellers liked the country, the rural dwellers showed a far stronger preference. 


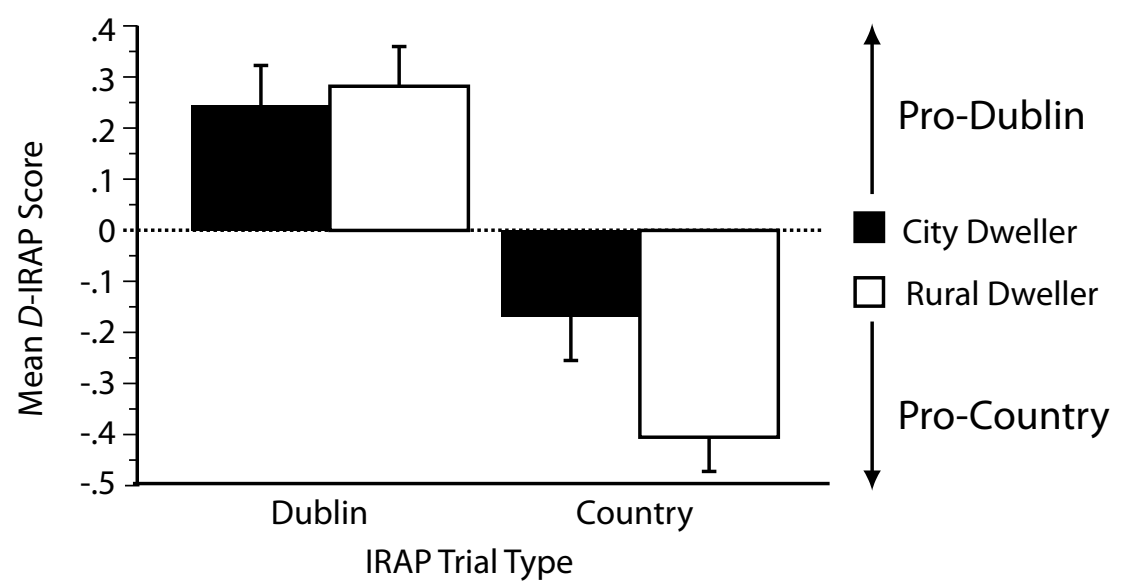

Figure 3. Mean IRAP D scores, with standard error bars, for Dublin and Country trial types for Dublin- and rural-dweller groups. A positive $D$-IRAP score indicates a pro-Dublin bias and a negative score indicates a pro-country bias.

The $D$-IRAP data were subjected to a $2 \times 2$ mixed repeated-measures ANOVA, with IRAP trial type (Dublin versus Country) as the within-participant variable and Group (Dublin versus rural dweller) as the between-participant variable. The ANOVA yielded a nonsignificant main effect for Group, $F(1$, $24)=1.09, p=0.3$, but a significant main effect for trial type, $F(1,24)=70.3$, $p<0.0001, \eta_{p}{ }^{2}=.74$. Critically, the interaction between Group and IRAP trial type also proved to be significant, $F(1,24)=4.7, p=0.04, \eta_{p}^{2}=.16$. Two planned-comparisons one-way independent-measures ANOVAs were used to compare the IRAP effect between the two groups for Dublin and Country trial types. The effect for the Dublin trial type was nonsignificant $(p=.7)$, but significance was reached for the Country trial type, $F(1,24)=4.6, p=.04$, $\eta^{2}=.16$. Overall, therefore, the inferential statistics supported the descriptive analyses: The two groups did not differ in their preferences for Dublin, but the rural dwellers showed a significantly stronger preference than city dwellers for the country.

One-sample $t$ tests were conducted to determine if the $D$-IRAP scores for each group differed significantly from zero. For the Dublin dwellers, the scores were significantly different from zero for Dublin, $t(12)=2.7, p=0.02$, but only approached significance for Country, $t(12)=-1.9, p=.08$. The rural dwellers showed significant differences from zero for both Dublin, $t(12)=3.4, p=0.005$, and Country trial types, $t(12)=-5.8, p<0.0001$. Thus, the rural dwellers were significantly positive about both Dublin and country life, but the Dublin dwellers were only significantly positive about Dublin life.

\section{Split-Half Reliability}

In order to calculate split-half reliability for the IRAP, two overall $D$ scores were calculated, one for odd trials and one for even trials. These two scores were calculated in the same way as the overall $D$-IRAP score (see step 10 above), except that the algorithm was applied separately to all odd trials and to all even trials. The split-half correlation between odd and even 
$D$-IRAP scores, calculated across all participants, proved to be moderate and significant, $r=.41, n=26, p=.03$, thus indicating a reasonable level of internal consistency, particularly for a response-time measure (see Nosek et al., 2006).

\section{Explicit Measures}

All of the explicit measures produced significant differences for participant type: city-life thermometer, $F(1,24)=10.98, p=.003, \eta^{2}=.31$; rural-life thermometer, $F(1,24)=23.64, p<.0001, \eta^{2}=.89$; city-life Likert, $F(1,24)=6.97, p=.01, \eta^{2}=.22$; and rural-life Likert, $F(1,24)=7.59, p=.01$, $\eta^{2}=.24$. In effect, Dublin dwellers reported significantly greater preferences for city life relative to rural dwellers, and rural dwellers reported significantly greater preferences for country life relative to Dublin dwellers.

\section{Implicit-Explicit Correlations}

A correlation matrix was used to analyze the correlations among the thermometer and Likert scales and the IAT and IRAP D scores (see Table 2). The IAT $D$ scores failed to correlate significantly with any of the explicit measures. For the $D$-IRAP, however, a number of significant or marginally significant correlations were obtained. Specifically, positive correlations were recorded for the city-life thermometers and Likerts for both Dublin and Country trial type effects, and a negative correlation was obtained between the rural-life thermometer and the Country trial type effect. (The correlation is negative because negative scores indicate a country preference on the IRAP.) In summary, the IRAP Country trial type effect correlated moderately, and the Dublin trial type effect weakly, with the explicit measures, but the IAT showed no such correlations. This pattern of correlations is consistent with the marginal group difference obtained for the IAT and the significant difference that was obtained for the IRAP between the two groups for the Country trial type effect.

Table 2

Explicit-Implicit Measures Correlation Matrix

\begin{tabular}{cccc}
\hline & \multicolumn{3}{c}{ Implicit measures } \\
\cline { 2 - 4 } Explicit measures & IRAP Dublin & IRAP Country & IAT \\
\hline City-life therm & $.399^{*}$ & $.414^{*}$ & -.078 \\
Rural-life therm & -.102 & $-.541^{*}$ & .104 \\
City-life Likert & $.368^{* *}$ & $.433^{*}$ & -.270 \\
Rural-life Likert & -.193 & -.322 & .106 \\
\hline
\end{tabular}

$* p<.05 . * * 0.07$.

\section{IAT-IRAP Correlations}

A series of correlations were used to determine if the IAT and IRAP effects predicted each other, but none of the tests were significant: IAT with Dublin IRAP trial type, $r=-.08, n=26, p=.70$; IAT with Country IRAP trial type, $r=.207, n=26, p=.317$; IAT with overall IRAP $D$ score, $r=.08, n=26$, $p=.70$. 


\section{Prediction of Group Status}

The ratings for the country Likert scales were subtracted from the city scales to produce a single overall score for each participant; the same subtraction was also applied to the feeling thermometers. Positive scores for either measure thus indicated a city preference and negative scores a country preference. A series of hierarchical logistic regression analyses were then conducted to determine if the two implicit measures increased the predictive validity of the two explicit measures.

\section{Thermometer Measure}

Two initial models were created. For both models the thermometer rating was entered as a predictor of group status (Dublin or rural dweller) in the first step. The thermometer proved to be a moderate and significant predictor of group status, $B=.07, p=.006$, accounting for $42 \%$ of the variance. For the first model, the IAT $D$ scores were entered in the second step, and this produced virtually no increment in predictive validity, $B=.87, p=.5$, accounting for $43 \%$ of the variance $\left(R^{2}\right.$ change $\left.=.01\right)$. For the second model, the Dublin and Country $D$-IRAP trial type scores were entered in the second step, and although both were nonsignificant, together they produced a larger increment over that of the IAT: Dublin, $B=-8.43, p=.1$, Country, $B=2.56, p=.4$, accounting for $61 \%$ of the variance $\left(R^{2}\right.$ change $\left.=.19\right)$.

\section{Likert Measure}

The same strategy was then applied to the Likert measure. The Likert proved to be a weak but significant predictor of group status, $B=.62, p=.01$, accounting for only $23 \%$ of the variance. When the IAT $D$ scores were entered into the first model (in the second step), this again produced a very small increment in predictive validity, $B=.99, p=.4$, accounting for $25 \%$ of the variance $\left(R^{2}\right.$ change $\left.=.02\right)$. When the Dublin and Country trial type $D$-IRAP scores were entered in the second step, both were again nonsignificant, while producing a larger increment over that of the IAT: Dublin, $B=-2.76, p=.1$, Country, $B=2.56, p=.2$, accounting for $34 \%$ of the variance $\left(R^{2}\right.$ change $\left.=.11\right)$.

\section{IAT and Overall D-IRAP}

Although the logistic regression analyses were nonsignificant for the implicit measures, the results do suggest that the two $D$-IRAP scores yielded greater predictive validity relative to the IAT. On balance, of course, the comparison could be unfair because the IAT regression models involved only one additional variable whereas the IRAP models involved two (the Dublin and Country $D$ scores). An additional two models were therefore created to determine if simply adding two implicit measures to the regression analyses would increase the predictive validity of the thermometer and Likert scales. Specifically, in the second step of each model, both the IAT and overall $D$-IRAP scores were entered. For both models, however, the increments were relatively small and nonsignificant: thermometer, IAT, $B=.51, p=.7$, overall $D$-IRAP, $B=-3.89, p=.27$, accounting for $48 \%$ of the variance $\left(R^{2}\right.$ change $\left.=.06\right)$; Likert, IAT, $B=.94, p=.4$, overall $D$-IRAP, $B=-2.5, p=.9$, accounting for $25 \%$ of the variance $\left(R^{2}\right.$ change $\left.=.02\right)$. 
In summary, therefore, the regression analyses suggest that the IRAP possessed greater validity than the IAT in predicting whether participants were Dublin or rural dwellers. Furthermore, even when the IAT and overall $D$-IRAP scores were entered into the regression model, the two separate IRAP measures still produced increments that were more than three times greater for the thermometer $\left(R^{2}\right.$ change $=.19$ versus .06$)$ and five times greater for the Likert measure ( $R^{2}$ change $=.11$ versus .02).

\section{Summary}

Overall, the results indicate that the IRAP was more effective at discriminating between Dublin and rural dwellers than the IAT. Specifically, the IAT produced only a marginally significant difference between the two groups, whereas the IRAP identified a significantly stronger preference of rural dwellers toward country life than that of Dublin dwellers. The IRAP also yielded stronger correlations with the explicit measures, but it did not correlate with the IAT. Finally, the trends observed with the logistic regression analyses suggested that the IRAP provided incremental predictive validity over the two explicit measures, but the IAT did not.

\section{DISCUSSION}

The IAT effects obtained in the current study were in the predicted direction (i.e., positive for Dublin dwellers and negative for rural dwellers), but the discrimination between the two groups was marginal. Furthermore, only the rural-dweller group showed a significant IAT effect. In contrast, the IRAP appeared to be more effective at discriminating between the groups than the IAT, based on a significant interaction effect. That is, the IRAP indicated that both groups responded positively toward Dublin and country life, but the mean $D$-IRAP score for rural dwellers was more than twice that of Dublin dwellers for the Country trial type. In effect, although both Dublin and rural dwellers liked country life, a much stronger preference was shown by the rural dwellers. Leaving aside the more effective group discrimination by the IRAP relative to the IAT, the results also highlight the analytic precision of the former measure. That is, the IRAP indicated that the groups differed not in their preferences for Dublin life but in their attitudes to country life alone, a conclusion that cannot be rendered from the relative nature of the IAT.

The explicit measures were effective at discriminating between the two groups. On these measures, greater preferences for city life were reported by the Dublin dwellers compared to rural dwellers, and greater preferences for country life were reported by rural dwellers compared to Dublin dwellers. Interestingly, the IAT failed to correlate with any of the explicit measures, but the IRAP displayed a number of significant and marginally significant implicit-explicit correlations. This discrepancy between the two measures is generally consistent with the fact that the IAT's discrimination between the two groups was only marginally significant.

The regression analyses showed that both explicit measures (thermometer and Likert) were significant predictors of group status. The addition of the IAT scores to either of the explicit measures provided a minimal increase in predictability. When both Dublin and Country $D$-IRAP trial type scores were added to either explicit measure, the predictability increased considerably. 
Although none of the increments in predictive validity proved to be significant, the data suggest a trend that favors the IRAP over the IAT in predicting whether participants were Dublin or rural dwellers. In any case, the present results indicate that the IRAP possesses no less predictive validity than the IAT.

Overall, the findings of this study suggest that the IAT discriminated less well between the Dublin and rural dwellers than the IRAP. This outcome was somewhat unexpected, given the extremely well-established status of the IAT and the fact that previous studies from our research group have yielded strong and predicted effects for the measure (Barnes-Holmes et al., in press; O'Toole et al., 2007). On balance, one of the main procedural differences between the IAT and the IRAP may well help to explain why the former measure produced a relatively weak effect in the current study. Specifically, the IAT involved asking participants to categorize examples of Dublin and country life with positively and negatively valenced words, whereas the IRAP simply asked the participants to relate Dublin and country life to the positive and negative words as similar or opposite (i.e., the IRAP did not present examples of Dublin or country). It is possible, therefore, that some of the Dublin and country exemplars employed with the IAT possessed unpredicted valences, and this served to attenuate the group discrimination. For example, some Dublin dwellers may have had a negative attitude toward "The Luas" or "Heuston Station," because they can often be overcrowded, but still have an overall positive attitude toward Dublin life. Similarly, rural dwellers may have possessed a negative attitude toward "cattle herds," because they can create delays on country roads, but still have an overall positive attitude toward country life. Of course, testing this explanation of the IAT's weak effect in the current study will require systematic empirical investigation, but noting it here does serve to highlight a confounding variable that may be important to consider when using the IAT but not when using the IRAP. ${ }^{3}$

The findings of the current study were also a little unexpected in that the difference between Dublin and rural dwellers' preferences for Dublin and country life was not as large as anticipated. Indeed, neither group showed a negative bias toward either Dublin or country living. Perhaps this finding is not that surprising, however, in light of a recent report on counterurbanization, migration toward rural areas, and the continuing expansion of the urban sprawl around Dublin city (Gkartzios \& Scott, 2005). Specifically, the report indicated that people wanted to be close to the city's facilities but still have the space of the country. Thus, many have moved to the expanding suburbs and try to have the best of both worlds. The strategy appears to be generally consistent with current findings in that participants from both groups responded positively to both Dublin and country life. Finally, of course, many city people spend their holidays in the countryside, and many rural dwellers travel to the city for shopping or entertainment, and thus both groups may experience "positive

3 It should also be noted that other factors may have played a role in producing the relatively weak IAT effect. For example, the Dublin-life targets were very specific and included various landmarks, but the Country-life targets were more general. Perhaps the IAT effect would have been different if more general targets were used for Dublin, such as "shopping mall" or "office block," or targets more specific to the Irish countryside were used, such as "Blarney Castle." In any case, insofar as the current IAT was influenced by the Dublin and Country target words in a somewhat unexpected manner, this would suggest another possible advantage for the IRAP over the IAT. Indeed, this advantage would extend over any other implicit measure that involves presenting multiple exemplars of the relevant attitude objects. 
exemplars" of the other area. Given that both IAT and IRAP effects have been shown to be sensitive to positive and negative exemplar interventions in the context of age-related bias (Cullen, Barnes-Holmes, Barnes-Holmes, \& Stewart, in press; Dasgupta \& Greenwald, 2001), it seems reasonable to assume that they would also impact on city versus rural biases.

A related issue concerns the fact that classifying participants as Dublin or rural dwellers proved to be more difficult than expected. For example, some of the participants who were classified as having lived in a rural area for 5 years or more were attending college and resided in temporary accommodations in Dublin, returning home on weekends. Participants in these cases considered themselves to be rural dwellers and were classified as such because they had spent most of their lives in a rural region. The effect of living in both areas on preferences for Dublin or rural life compared to living in one area remains unknown, and thus this factor may have influenced the results. Future studies might attempt to select rural dwellers who have resided in one region only, although in modern Ireland, with its patterns of migration, this will become increasingly difficult.

In summary, therefore, the current study has provided additional support for the IRAP as a measure of implicit attitudes by comparing it directly to the IAT using a known-groups approach. The IRAP appeared to provide better discrimination between Dublin and rural dwellers' implicit attitudes than the IAT, although the difference between the measures may be due to a procedural artifact rather than the superiority of the IRAP per se. Additional research will be needed to determine if the two measures do indeed differ in terms of their predictive validity. Nevertheless, the current findings indicate that the IRAP has clear potential as a measure of implicit attitudes and is thus worthy of further systematic investigation.

\section{REFERENCES}

BARNES-HOLMES, D., BARNES-HOLMES, Y., POWER, P., HAYDEN, E., MILNE, R., \& STEWART, I. (2006). Do you really know what you believe? Developing the Implicit Relational Assessment Procedure (IRAP) as a direct measure of implicit beliefs. The Irish Psychologist, 32, 169-177.

BARNES-HOLMES, D., HAYDEN, E., BARNES-HOLMES, Y., \& STEWART, I. (2008). The Implicit Relational Assessment Procedure (IRAP) as a response-time and event-related-potentials methodology for testing natural verbal relations: A preliminary study. The Psychological Record, 58, 497-516.

BARNES-HOLMES, D., MURTAGH, L., BARNES-HOLMES, Y., \& STEWART, I. (in press). Using the Implicit Association Test and the Implicit Relational Assessment Procedure to measure attitudes toward meat and vegetables in vegetarians and meat-eaters. The Psychological Record.

CULLEN, C., \& BARNES-HOLMES, D. (2008). Implicit pride and prejudice: A heterosexual phenomenon? In T. G. Morrison \& M. A. Morrison (Eds.), Modern Prejudice (pp. 195-223). New York: Nova Science.

CULLEN, C., BARNES-HOLMES, D., BARNES-HOLMES, Y., \& STEWART, I. (in press). The Implicit Relational Assessment Procedure (IRAP) and the malleability of ageist attitudes. The Psychological Record.

DASGUPTA, N., \& GREENWALD, A. G. (2001). On the malleability of automatic attitudes: Combating automatic prejudice with images of admired and disliked individuals. Journal of Personality and Social Psychology, 81, 800-814. 
DE HOUWER, J. (2003). The extrinsic affective Simon task. Experimental Psychology, 50, 77-85.

DE HOUWER, J., \& DE BRUYCKER, E. (2007). Implicit attitudes toward meat and vegetables in vegetarians and non-vegetarians. International Journal of Psychology, 42, 158-165.

GKARTZIOS, M., \& SCOTT, M. (2005). Countryside, here I come: Urban-rural migration in the Dublin city-region (Planning and Environmental Policy Research Series Working Paper 05/01). Department of Planning and Environmental Policy, University College Dublin.

GREENWALD, A. G., MCGHEE, D. E., \& SCHWARTZ, J. L. K. (1998). Measuring individual differences in implicit cognition: The Implicit Association Test. Journal of Personality and Social Psychology, 74, 1464-1480.

GREENWALD, A. G., NOSEK, B. A., \& BANAJI, M. R. (2003). Understanding and using the Implicit Association Test: I. An improved scoring algorithm. Journal of Personality and Social Psychology, 85, 2, 197-216.

HAYES, S. C., BARNES-HOLMES, D., \& ROCHE, B. (Eds.). (2001). Relational Frame Theory: A post-Skinnerian account of human language and cognition. New York: Plenum.

MCKENNA, I., BARNES-HOLMES, D., BARNES-HOLMES, Y., \& STEWART, I. (2007). Testing the fake-ability of the Implicit Relational Assessment Procedure (IRAP): The first study. International Journal of Psychology and Psychological Therapy, 7, 253-268.

NOSEK, B., \& BANAJI, M. R. (2001). The go/no-go association task. Social Cognition, 19, 625-666.

NOSEK, B. A., GREENWALD, A. G., \& BANAJI, M. R. (2006). The Implicit Association Test at age 7: A methodological and conceptual review. In J.A. Bargh (Ed.), Social psychology and the unconscious: The automaticity of higher mental processes (pp. 265-292). Philadelphia: Psychology Press.

O'CONNOR, P. (2005). Local embeddedness in a global world: Young people's accounts. Young, 13(1), 9-26.

O'HORA, D., BARNES-HOLMES, D., ROCHE, B., \& SMEETS, P. M. (2004). Derived relational networks and control by novel instructions: A possible model of generative verbal responding. The Psychological Record, 54, 437-460.

O’HORA, D., PELÁEZ, M., BARNES-HOLMES, D., \& AMESTY, L. (2005). Derived relational responding and human language: Evidence from the WAIS III. The Psychological Record, 55, 155-174.

O'TOOLE, C., BARNES-HOLMES, D., \& SMYTH, S. (2007). A derived transfer of functions and the Implicit Association Test. Journal of the Experimental Analysis of Behavior, 88, 263-283.

STEWART, I., BARNES-HOLMES, D., \& ROCHE, B. (2002). Developing an ecologically valid model of analogy using the relational evaluation procedure. Experimental Analysis of Human Behavior Bulletin, 20, 12-16.

STEWART, I., BARNES-HOLMES, D., \& ROCHE, B. (2004). A functional analytic model of analogy using the relational evaluation procedure. The Psychological Record, 54, 531-552.

VAHEY, N., BARNES-HOLMES, D., BARNES-HOLMES, Y., \& STEWART, I. (in press). A first test of the Implicit Relational Assessment Procedure (IRAP) as a measure of self-esteem: Irish prisoner groups and university students. The Psychological Record. 